\title{
Introduction: how can we enhance research?
}

Why are some academics more successful in their research activities than others? Are there activities that researchers can engage in that enhance the quality of their own and others' research? Can research leaders stimulate greater research output by their colleagues?

This book suggests good practice and makes recommendations that are designed to enhance your own and your colleagues' research potential and achievements. It is based on decades of experiences, observations, reflections, guidance, advice, and covert and overt practices and nudges that I experienced, observed, heard about or implemented. I have listened and learned from esteemed colleagues located at a variety of universities and research institutes, and I have tried to put many of these into practice as a professor, department research leader, head of department, interim head of department, researcher and as a colleague. This book summarises those tips, ideas and lessons with the hope of raising awareness that there are opportunities to purposefully and collectively increase the quality of our community's research output.

This book presents 100 tips and initiatives that can influence research behaviours and enhance academics' social norms. Some tips draw on conversations with researchers about their experiences, pleasures, frustrations, reflections and/or achievements at work. Some tips draw on conversations with researchers who recognise real and/or perceived barriers to and accelerators of their and others' research output. Some tips draw on my own experiences, while others are grounded on observations of departments that attempted, albeit based on goodwill, to impose structures designed to support research but which inadvertently hindered research. ${ }^{1}$

These practical tips and initiatives can be implemented by individual researchers and their research leaders. Many of these tips are simple and easy to put into practice, but they are frequently overlooked, trivialised, or not even recognised for their true benefits. When prioritised, they can culminate in enormous benefits for individual researchers and for the research culture within or across interconnected disciplines. Through this book, I hope to stimulate researchers and research leaders to discuss these initiatives with their colleagues in an attempt to enhance individual research activities and depart- 
ment research profiles and, most importantly, boost our speed and accuracy of understanding across the social sciences.

\section{WHAT IS THE MAIN ARGUMENT OF THIS BOOK?}

I will argue that we all need to frequently surround ourselves with people who challenge us in a supporting manner, make us hungry for knowledge, make us even more curious, provide the academic freedom to imagine the unimaginable, and positively motivate us. Research must be lived, and how you live it will influence the pace at which you improve; those who live their research the most will eventually become the senior and more recognisable leaders in their field. When researchers receive emotional and intellectual support, they feel more empowered, excited and energised to produce more and better-quality research. To progress you need both a network of support and the right personal attitude. Supportive, constructively critical working environments generate higher levels of employee well-being (Lopes, 2011) ${ }^{2}$ and higher levels of well-being are experienced by individuals in organisations that facilitate autonomy and personal growth (Turban and Yan, 2016). ${ }^{3}$

Connected with this is the paradox of intention. Researchers who are happy and enjoy their research journey and possess intrinsically informed and achievable goals are likely to be the most productive. The important thing here is not that their happiness and motivation are linked to the achievement of those goals, but instead that their happiness and motivation are associated with the journey towards achieving those goals. For the journey to be enjoyable, the researcher needs to feel that the research has meaning, and for something to have meaning requires you to see its purpose. The purpose of your research lies integrally within you: you need to know what you are interested in most and what academic insights you wish to contribute in order to enjoy your journey. This is what keeps you going when you are knocked back by a desk rejection or an unfavourable referee report. Researchers should reflect on what gives them 'flow' in their journey - i.e. what gives them a mental state where they are fully engrossed in what they are doing with a feeling of energy, focus and undivided engagement - and they need to ensure that they know how to get that flow back when they lose it.

Once you have your flow, you will recognise that your job brings you the greatest amount of joy, and it will turn into a marvellous and engrossing hobby. You will enjoy progressing along the journey with others you have found along the way who are also fascinated by a topic. You could even synchronise your efforts, harmonise your activities and schedules, and socialise your research activities. Having colleagues who are progressing along a similar journey intensifies the feeling of purpose and personal flow. In Thinking, Fast and 
Slow, Daniel Kahneman $(2012)^{4}$ banters that you can run 500 miles, but you can run 500 more miles if you are accompanied by your own 'Amos'.

Research leaders need to know how to help individuals remain in or return to their flow. Two of the most important things that I learnt about research are that (i) we have to enjoy the journey unreservedly in order to make an important contribution, and (ii) we should cultivate our research journey almost every day in order to ensure that we receive the creative and imaginative benefits of flow in our research lives. When you fully enjoy your research, and when you possess those intrinsic motivating forces, then you will be highly productive. ${ }^{5}$ The more you enjoy something, the more you want to practise it; persistence reinforces practice; and the more you practise something, the better you get at it. ${ }^{6}$

We have all met academics who have been so demoralised and discouraged by poor management and administrative burdens ${ }^{7}$ that they seem to accept that research is something that they will never have the capacity to undertake properly anymore; they seem to have given up and are resigned to a frustrating and unfulfilling academic career. Their flow has been disrupted so much that they do not believe they will ever experience it again. These colleagues need to surround themselves with uplifting and inspiring colleagues in order to give them hope that they will meet their aspirations. ${ }^{8}$ Indeed, an insight of Maslow's (1943) $)^{9}$ Hierarchy of Needs is that managers can shape the conditions that create a researcher's aspirations and drive to reach those aspirations. Throughout this book, I argue that it is not only a research leader's responsibility to create these conditions but also the responsibility of the researcher and the researcher's colleagues. This is the case not only for the achievement of the pinnacle of self-actualisation, but also for the general fulfilment and opportunities for personal and academic growth and development: research leaders are necessary for this effect but not sufficient because colleagues build on, refine and magnify the research leader's effect across the department.

If you are lucky enough to have the following research culture characteristics within your department, then you will know that you are able to feed off each other's enthusiasm and energy, iterate and nurture the research culture as a fuel for success, and create, maintain and enhance the department's research engine:

- intrinsically motivated academics who are dedicated to a cause,

- colleagues who have a group-centred (rather than individualistic) attitude and a strong sense of belonging to a part of their discipline,

- an attitude of support for research and for each other,

- an attitude of mutual respect for research and for each other, and

- an empowering attitude to undertake research with academic freedom. 
This book suggests ways to install these research culture characteristics in your colleagues, conditional on them being open to receiving that guidance. It also suggests ways to enhance the belonging, intrinsic motivations, support, mutual respect and empowerment of academic researchers across a department.

Ask any successful researcher about how they achieved what they have done and they will typically answer in either or both of the following ways:

(i) they have not yet achieved their potential because they are very inquisitive and there is so much more to learn and contribute to along their journey of discovery, and

(ii) they have received vital feedback and guidance from peers, colleagues and a wider audience that has enabled them to identify their own oversights, and that social interaction and feedback has been of prime importance in enhancing their development.

Our greatest advisors who steer our research achievements, interests and abilities are our closest collaborators. They excel in giving supportive, critical, insightful and useful feedback. Yes, that feedback can be frustrating at times, perhaps excruciatingly so, but then sooner or later we realise that they make a well-meaning and insightful point, and that if we understand their feedback and respond to it appropriately then it will improve our work. What we achieve is in no small part because of the support we receive from our academic family.

You cannot achieve efficiency or be fully effective by working on your own.

Recent investigations into why Sweden is a hotspot for innovation and technology, even though it has a population of only ten million citizens, reveal that this propensity may be related to the discouragement of extravagant displays of wealth, social opposition towards the revelation of success and the deconstruction of hierarchies. There appears to be greater needs-based collaboration and less competition in an environment where there are fewer competitive stress points, ${ }^{10}$ when those stress points are performance enhancing ${ }^{11}$ and when the feeling is that you are better off working at the same level as everyone else. ${ }^{12}$ Similarly, a productive research group is one where there is togetherness in a clearly supportive team, with all researchers dedicated to reaching their goals, who use their academic freedom to pursue their research interests, who feel empowered to take the responsibility they need, and who encourage each other to do the same without any feelings of inferiority or concerns about their inability to compete. Active and prosperous researchers will value this collegiality (if they recognise it) and will not want to leave behind such a culture, as they would lose their identity and their source of happiness. ${ }^{13}$ 


\section{WHOM IS THIS BOOK FOR?}

This book has two main target audiences: first, I recommend this book to those who want to know how to improve the quality of their own research. This includes those new to social science research, those who have experienced a slowdown in their research output but want to reinvigorate it, and those who wish to publish in higher rank journals. Second, I strongly recommend this book to those with responsibility for enhancing the research output of their colleagues across the social sciences.

The greatest senior researchers that I have had the fortune to meet tend to be open, cooperative and approachable, and they informally undertake significant pastoral duties and covertly care for their colleagues. It is unfortunate, therefore, that many of these academics are too humble to take on formal head of department or research leader duties. These essential, primary researchers have expansive, informal networks and are the people researchers often go to for an informal chat, because that person is not judgemental of the person but is supportive, constructively critical and encouraging of research activities. It is my observation that excellent Heads of Department have exemplary and intricate prior knowledge of how to coordinate and enable their colleagues, and therefore recruitment of a Head of Department from outside the institution is inevitably going to be challenging for all.

This book is also for academics who want to know how to make other academics' work lives more enjoyable, and a significant part of this is the ability to allocate more quality time for lateral thinking. Lateral thinking requires frequent reflection and mental gymnastics about content and about the relevance of different perspectives; this requires a desire to immerse oneself into those perspectives and to assimilate the ideas.

Finally, this book is for those academics who enjoy their work and are already productive but wish to know how lucky they are and how to make it an equally enjoyable place to work for other up-and-coming and/or experienced researchers. When we achieve our 'flow', ${ }^{14}$ research becomes a joyful journey. This flow galvanises us to push ourselves to our inventive extremes and to participate fully in research activities that can improve society.

\section{WHY DO WE RESEARCH?}

You do not undertake research activities simply for yourself; neither are you doing it simply for other researchers. You are undertaking research activities in order to help uncover and clarify knowledge. Once academics realise this, and it is resisted more in some disciplines than others, so the ceremonial component of knowledge creation is relegated and instead we stimulate and foster the 
instrumental part of research. Our modest contributions to the literature could enhance all of our understandings and make our knowledge and understanding of the world that tiny bit more comprehensive. Ever since Paine engaged with science and research and wrote his Age of Reason, ${ }^{15}$ we have understood that this is the correct researcher mindset. We research and create scientific knowledge because we want to increase our collective understanding of the world; we do not conduct research simply to fulfil our personal curiosities.

In a supportive research culture, it is crucial to recognise that your colleagues are not your competitors! They are your co-workers and you all share a common goal, which is to uncover new knowledge. This book underscores the importance of building and maintaining a research culture and the importance of supportive, proactive and responsible behaviours by both individual researchers and research leaders in order to nurture and strengthen collegiate attitudes. Once you collectively create and maintain the appropriate set of research attitudes and behaviours, your department will obtain a research 'flow' - i.e. a particular collective state of mind ${ }^{16}$ - where your research culture enables you to perform at your best and makes you a constructive element of the wider research community.

Finally, the book accentuates the vital role that a research leader performs in nurturing and improving their department, and it takes a personal touch (introverted ${ }^{17}$ or otherwise) to create that productive research culture. Although the Internet and email have accelerated and improved our ability to connect with colleagues, it seems that these have driven an impersonal wedge between us, as we have reduced our prioritisation to connect meaningfully with each other with integrity and in a humanistic way.

\section{NOURISHING MOTIVATIONS}

The vast majority of academics did not enter the profession because they wanted to win a Nobel Prize or obtain some other type of critical acclaim. Most entered the profession because they realised that they were relatively good at something, that they were enormously interested in something and that they wanted to make a difference. This observation is nothing new: Dolan and Kudrna (2016) ${ }^{18}$ emphasise that feelings of purpose and pleasure motivate our choices about what to do. Some motivations are intrinsic while others are extrinsic.

The difference between a successful person and others is not a lack of strength, not a lack of knowledge, but rather a lack of will. (Vincent Lombardi)

In my experience, intrinsic motivations and genuine personal interest dominate and drive researchers' engagement in research activities, especially 
over the long run, albeit with a judicious sprinkling of external relevance. Unfortunately, the current trajectory of the academic system, especially within the UK but also across other predominantly English-speaking areas of the globe, seems to be towards escalating mechanisms that enhance extrinsic motivations, and this trajectory changes researchers' foci and reduces their natural and intrinsically driven engagement with and enthusiasm for their research.

Various studies reveal the behavioural effects of financial incentives ${ }^{19}$ and highlight that any beneficial effect (when there is one) comes to an end in a short period of time. Frey $(1993)^{20}$ shows that extrinsic motivations crowd out the beneficial effects on productivity of high worker morale. Ariely et al. $(2009)^{21}$ emphasise that many understandings about incentives and policies are wrong, that the underlying assumptions regarding the mechanisms are seriously misguided, and that some extrinsic incentives actually have the reverse effect on productivity as they reduce effort. Ariely et al.'s results powerfully illustrate that financial (extrinsic) incentives decrease an individual's performance, and part of this is because it crowds out professional pride.

Most incentive structures also ignore and undermine the importance of morals. Creating personal financial reward systems or other structures designed to incentivise greater individual researcher productivity crowds out morals and intrinsic motivations for research, demoralises academics, splits departments into 'them and us', restricts academic progress, and constrains wider thought. This is consistent with the ideas of Samuel Bowles (2008), ${ }^{22}$ who emphasises that incentives that appeal to self-interest fail when they undermine the moral values that lead people to act altruistically or in other public-spirited ways, which is a kind of negative synergy between economic incentives and moral behaviour. Specifically, Bowles (2008, p. 1605) argues that "economic incentives may diminish ethical or other reasons for complying with social norms and contributing to the common good" and that policies that appeal to economic self-interest affect the salience of ethical, altruistic and other social preferences.

Extrinsic incentives encourage researchers to work on tasks that are easy to monitor, such as recordings of publication output, rather than ones that are important for the substantive stock of knowledge, which are much harder to measure and often are not appreciated fully at the time of publication and therefore it is impossible to gauge their impact effectively at any point in time. For instance, the number of conference trips and associated costs can be easily measured by a research administrator, but the motivating effects of attending conferences and their spillover effects to a department's research culture cannot be measured with any accuracy and their impact fluctuates across departmental colleagues.

Some research seems to be produced simply to satisfy extrinsic motivations. Nosek et al. (2012) ${ }^{23}$ and Smaldino and McElreath (2016) ${ }^{24}$ argue that institu- 
tional incentive structures and the cultural transmissions of research practices lead to the production of research that has extremely negligible significance. Social forces encourage ceremonial conformity with a discipline's expectations of pedantic dexterity - such as the drive to visibly illustrate one's ability to present eloquent mathematical formulae - that do not necessarily assist in the advancement of real social science thought or practice, and can instead create a language that excludes others.

Ariely et al. (2011, p. 192) ${ }^{25}$ argue that the presence of incentives illustrates that an institution does not trust the intrinsic motivations of its researchers to work effectively. Their research suggests that incentive mechanisms could even damage an organisation's performance because they may demoralise researchers who are seriously interested in improving our knowledge for society's benefit. Indeed, fuelling extrinsic motivations could damage research and innovation, especially if individual research activities driven by intrinsic motivations tend to help society. Famously, Titmuss $(1970)^{26}$ shows that paying people to donate blood broke established social norms about voluntary blood contributions and reduced the fraction of people wishing to donate blood. Similarly, breaking the link between researchers' intrinsic motivations and their social benevolence encourages researchers to be more selfish and myopic, and thereby reduces their prioritisation to produce research that benefits society.

Genuine intrinsically motivated interests fundamentally shape our levels of enjoyment of research activities and prevent us giving up on research ideas when they become too challenging. In contrast, extrinsic returns encourage us to make frequent, conspicuous and petite incremental achievements, in ever more complex ways, in order to gain recognition for numerous contributions. Extrinsic motivations do not encourage us to investigate something that is extremely meaningful and important to society, especially when the socially informed market for knowledge prioritises something else. Policies that create extrinsic rewards end up socialising the costs while privatising the benefits.

In my experience, most academic researchers are intrinsically motivated to contribute to society and to solve a socially beneficial problem, but trying to motivate them through extrinsic rewards can destroy this altruistic tendency and encourage them to produce output that contains conspicuous and ceremonial detail. It is my view that if we encourage behaviours that are consistent with carefully observed, socially benevolent and celebrated intrinsic motivations, then we can achieve greater good than if we use extrinsic motivations associated with metrics, ranks, monetary returns or other market-imposed structures. 


\section{MY SOAPBOX: SUPPORT AND ENCOURAGE}

A university must have an institutional environment that values the cross-fertilisation of ideas and skills from experienced to less-experienced staff and back again. There are some institutions where the researcher is left to their own devices and is expected to produce research almost in isolation. In other institutions, the culture is so competitive that it frowns on collaborative and mutually supportive behaviour, often sourcing justification from research assessment exercise rules that state that a journal article can only be submitted under one resident researcher's name. These competitive cultures may be effective for some narcissistic researchers (and yes, such researchers definitely exist!), but knowledge production progresses much faster when people discuss their research openly, constructively and constructively critically, and when colleagues see mutual benefits from doing so. The act of providing constructively critical feedback to colleagues is grounded in the principal objective to improve the quality of the work. Furthermore, the best scholars actively learn from constructive criticism: they see the positives and appreciate the feedback.

The best research leaders, who combine generosity and compassion, already know that emotionally and intellectually supporting their colleagues takes a huge amount of time, energy, patience and perseverance; they also know that this effort pays off. Böckerman et al. $(2020)^{27}$ even find that there is a clear positive correlation between supervisory support and job control, with employee well-being negatively correlated with job-related stress. Research leaders (and heads of department) have a duty to understand what drives and enhances their colleagues' achievements and dedication, and the accumulation of this person-specific knowledge across a department requires a considerable amount of time. Research leaders must make time and must be given time to comprehend what their colleagues really need in order to excel, which sometimes is not what the junior researcher will necessarily demand. Bringing in a research leader or head of department from outside of a department or university should only be done if no other option is available and if a big structural change is required. Appointees from outside the department will require many months to be cognisant with the idiosyncratic intrinsic motivations of each and every colleague, and many of their efforts and achievements will inevitably be suboptimal.

We naturally adopt a research-leading, nurturing role when we mentor $\mathrm{PhD}$ students. Research leaders have the responsibility to nurture their colleagues, and this is why we are an academic family. Our best interests should be that all members of our family gain satisfaction from their efforts. ${ }^{28}$ Moreover, as the best parents intuitively know, the support provided by research leaders to their colleagues must be selfless and reliable. A researcher should be given 
complete freedom to follow his or her own talent and intuition, and they should feel supported and not experience fear when they face a challenge or wish to proclaim an idea.

Great minds discuss ideas. Average minds discuss events. (Anna Roosevelt)

Research leaders must be socially benevolent and want to get the best out of their colleagues. They should be actively interested in what their colleagues need, aware of what barriers (real or perceived) are in their colleagues' way and actively offer ideas to help. A research leader is there to guide their team forward while also leading by example. Proponents of self-determination theory, such as Deci and Ryan (2000), ${ }^{29}$ argue that the conditions that incentivise intrinsic motivations are those that support autonomy, competence and relatedness. Nonetheless, actions that help one or a group of colleagues may be completely different to the actions that succeeded when a research leader was learning their trade. An effective and responsive research leader watches, listens, learns, understands, anticipates and reacts to the needs of their colleagues. ${ }^{30}$ Much of what I advocate in this book is in line with the ideas of transformational leadership. ${ }^{31}$ I advocate that research leaders need to:

- ensure that academic research (not externally funded research grants) is and remains the priority,

- raise awareness of the higher quality of academic work that can be achieved,

- encourage the mutually beneficial sharing of ideas,

- foster a culture of reciprocal support and respect, and

- coach using a supportive and encouraging language that is understood by everyone involved.

This means that the best research leaders:

- have a personal approach. They treat people as individuals and humans, not as machines or robots. Research leaders need to go above and beyond the norm to make sure people feel welcome, respected, and part of the team.

- recognise each colleague's potential and actual beneficial impact on the department. Academics are invariably people who want to make a beneficial difference and, if research leaders can explicitly recognise this in individuals, the colleague will feel valued and will contribute more to the team. ${ }^{32}$ Some researchers will need this reassurance more than others, depending on their insecurity and self-esteem.

- talk to people verbally and face-to-face. Use Zoom or Skype if there is no alternative but be mindful that wholesome rapport is attained when you are in the same physical, relaxed and unconfrontational space. Personal 
appreciation is communicated very poorly via email and can be embarrassing in meetings.

The best mentor and leader that I ever had was Professor Mike Campbell. Mike was an exemplar of a first-rate transformational leader who communicated very positive expectations to his colleagues and inspired, empowered and stimulated us all to exceed our levels of performance by nurturing our common interests, enthusiasm and motivations while challenging us to be innovative and creative. The humble and late Professor Mike Campbell was also an advocate in social justice and will forever be sadly missed.

The behaviours of those around you will shape your behaviours towards others. Of course, these lessons on how to interact with others commence and are learned in childhood, and then extend across our entire lives. Nevertheless, a researcher's early and updated experiences with their own research leaders will subsequently shape and revise their own interpersonal behaviours. A positive, nurturing and supportive experience with a research leader can fill you with joy and encourage you to help others, not for thanks or recognition but simply as a way of passing on the beneficial ambiances that have already been granted to you. This is how a healthy and constructively critical research culture reproduces itself in a sustainable, rewarding and expanding manner. Negative experiences with a research leader or senior member of staff (such as belittling, passive aggressiveness or gaslighting) will only encourage you to dismiss your colleagues' efforts, install in you an incorrect and shameworthy impression of superiority, and make you reticent to help others. Indeed, it appears that different disciplines have different cultures and therefore have different needs for this book. ${ }^{33}$

This book is unashamedly based on the belief that a department with a supportive and challenging (as opposed to undermining or gaslighting) leadership, which has a high degree of competence and values mutual respect, and where the environment is open, welcoming, non-hierarchical and constructively critical, is not only a convivial place to work but also one where research output thrives. This perspective is not new, as it has been forcefully promoted by Bland et al. (2005). ${ }^{34}$ If you combine those work environment characteristics with unambiguous and clearly communicated goals, then research will flourish (Ryan and Hurley, 2007). ${ }^{35}$ There are empirical findings which suggest that an environment with high workloads and a lack of institutional support for lateral thinking limits academic productivity, ${ }^{36}$ while other findings emphasise that unfair leadership, role conflicts and inequality reduce research output. ${ }^{37}$ Similarly, an institutional environment that promotes a climate of anti-intellectualism (Jacoby, 2009) (38 $^{38}$ destroys lateral philosophical thought. Hence, academic policymakers interested in strengthening the production of research output should provide their researchers with a supportive and 
constructively critical workplace. A supportive culture was summarised by one of my former exemplary colleagues as

the comfort of knowing you are well-considered, with full understanding of what you are, and with earnest care for your best. (Anon.)

Installing these values and norms in a department is difficult and changing a research culture for the better takes several years at a minimum and cannot be accomplished without the support and buy-in of senior colleagues. It cannot be achieved overnight as researchers' expectations and ways of working must evolve with the transition towards that supportive, open culture. When individuals in a department suffer from functional fixity and do not buy-in to a cultural transition, then transformational efforts will be ineffective.

Intelligence is the ability to adapt to change. (Stephen Hawking)

Small changes can generate huge benefits (Thaller and Sunstein, 2008). ${ }^{39}$ Senior and more experienced researchers must be willing and open to engage in the sharing of knowledge and the supporting of less experienced researchers. They must also be willing to use their experience to read and provide constructive and insightful feedback on their colleagues' manuscripts, and motivate and support colleagues by providing them with opportunities to discuss research in ways that constructively and usefully challenges their ideas in an utterly non-dismissive manner. Senior researchers need enough time and resources to be able to support their colleagues, as well as time to focus on writing their own research so that they can lead by example. Research leaders, therefore, need the utmost trust, respect and support of their own line managers too. Research leaders must be humble, approachable, resilient, persuasive, supportive and usefully critical towards their colleagues. Research leaders should use nuanced language intelligently when responding to the needs of individual colleagues, given those colleagues' personalities and temporal needs.

Experienced researchers need to collaborate with other experienced researchers too in order to keep their own research knowledge and tempo up to date. When experienced researchers collaborate visibly, their colleagues recognise that cooperation is a benevolent and mutually beneficial process. Learning to balance personal research and departmental leadership skills efficiently takes years of experience, but the promotion and appointment of someone as a research leader who does not have these skills only weakens the research culture. Benson et al. (2019) ${ }^{40}$ emphasise that the best worker is not always the best candidate for a managerial position, and they question whether firms promote the best potential manager or the best worker in their current job. Research leaders must be experienced in academic research (some 
may say this is obvious, but I know it is not obvious to some). They also need to understand the trials and tribulations of academic research and be able to guide less experienced colleagues through these experiences, as without those experiences the research leader is unable to lead by example.

In some departments, research leaders feel threatened by their junior colleagues because they are worried that their junior colleagues will overtly challenge their superiority, and then they put those junior colleagues down rather than trying to inspire and encourage them. These people should not be promoted to leadership roles, as a true research leader should want their junior colleagues to surpass them (irrespective of that time delay), because the sign of a great research leader is when their less experienced colleagues progress quickly and rapidly improve the quality and impact of their research. Note that the important word is 'improve', which refers to a change rather than remaining at the same level irrespective of how high a level that is. Good research leaders create an inclusive culture that facilitates and enables their colleagues to improve at their optimal pace.

I think that we can't go around measuring our goodness by what we don't do, by what we deny ourselves, what we resist, and who we exclude. I think we've got to measure goodness by what we embrace, what we create, and who we include. (Robert Nelson Jacobs)

Research leaders should want their colleagues to learn from their research leader's strengths and mistakes. Junior researchers, indeed all academic researchers, need someone to guide them and show them different ways of doing things. This guidance includes the provision of knowledge about what happens when mistakes are made, because it is only by making mistakes when pushing research boundaries forward that we eventually realise how to push boundaries in a more proficient manner. The avid and enthusiastic researcher who wants to improve their research should

- thoroughly embed themselves in the research culture,

- push their own boundaries and get things wrong no matter how uncomfortable those learning experiences can be,

- surround themselves with thinkers who are more imaginative than they are, and

- encourage colleagues to try to be better than they are, for it is only by surrounding yourself with more able colleagues that you are also able improve.

If you are the smartest person in the room, then you are in the wrong room. (Michael Saul Dell) 
At the individual level, it is not merely how good you are at research at a particular moment that is important, irrespective of the connotations of a research assessment exercise. Instead, we should actively consider how good you could become and what could be done to ensure that you achieve your potential. The most important role of a research leader is to ensure that all of their research colleagues are able to thrive.

It is similar at the department level: it is not how good at research you are collectively at a point in time that counts; it is about how good you all could become and what could be done to ensure that you all achieve your potential. The research atmosphere should be dynamic and forward thinking, with a clear purpose and implementation strategy that enhances quality and the sustainable growth of policy-relevant research. We have a responsibility as academic scholars to commit to do our individual and collective best and to repay society's support and investment in our education and training through the advancement of knowledge and understanding.

\section{TREAD WITH CARE}

Senior research staff (research leaders and all fellow professors) shape the research atmosphere within a department. Their role is to lead by example, be open to collaboration, provide constructive feedback and offer support to all of their colleagues (irrespective of differences in ontological or epistemological approach), and, very importantly, have their doors open to welcome all colleagues should they require help or advice. The actions of senior research staff can either enable their colleagues to excel and succeed, or unwittingly discourage and demoralise them so they underperform.

Senior research staff should take credit and immense pride when a department improves under their collective leadership. Senior research staff should also take the collective blame when their department is not performing, when either the policies or actions need to change, or the research leaders need to change.

Some researchers need their colleagues to open doors for them, while other researchers barge through the doors themselves. Given the appointment of senior staff with different research backgrounds, ${ }^{41}$ interests and networks, it is impossible for the mix of senior staff members to be able to open an informed range of doors for all of their colleagues. When a colleague perceives others receive more help than they do, a sense of disadvantage and unfairness can permeate through a department. Control of that damaging narrative is imperative and requires cooperation ${ }^{42}$ across all of the senior staff who should distinguish those divisive (conscious or otherwise) behaviours and reunite their department so that they work together in a supportive manner once again. 
Research leaders and other senior researchers could stop opening doors for their colleagues just in case some feel relatively disadvantaged or discouraged by a perception that they are receiving less support. However, this would be totally the wrong thing to do. Research leaders should be visibly opening doors for as many of their colleagues as possible, but they should be clear that they have tried when some doors remain shut or when they did not see an opportunity. All colleagues need to know that doors open episodically, and it can be a period of time until the right doors open. Patience is a virtue, but also required is the belief and acceptance that senior colleagues are proactively supporting all colleagues, without exception. Unfortunately, some colleagues will not believe and accept this, rightly or wrongly, and become combative to stake a claim.

Of course, people's insecurities and neediness do vary over time and this can be unpredictable and even unobservable if the research leadership staff do not know their colleagues well enough; even if they do notice a change in behaviour then they may misinterpret that change. These leaders need to have the capacity and the personality to listen properly to their colleagues and then be responsive to their needs either by focusing on opening more doors for them or by correcting misconceptions.

Opening different doors brings different benefits to different colleagues but often in unforeseeable ways. It is important that people are aware that support is available and provided, and that senior staff are working to help them realise their potential. When people do not feel supported, which can be different to the support that they really receive, then that is when they often decide to leave and join a competitor research institution.

\section{MAKING EVERYONE SUCCESSFUL}

There are four levels of interwoven responsibilities that collectively generate an excelling research culture. First, it is the responsibility of senior researchers to create a supportive research culture. Second, the primary responsibility for all researchers is to create high-quality substantive research outputs. There are many ways to achieve a successful research career, and these seem to vary within and across disciplines, the position within a career and the levels of enthusiasm for the topic by the researcher and by others. Third, once you feel that you are making progress in your research, the next step is for you to enable your peers to develop their own research by helping to remove any barriers that inhibit their progress. Fourth, and the pinnacle of any highly active research department, is to ensure that everyone supports and helps each other by, for example, taking the time to read and provide feedback on each other's research. These stages are hierarchical and sequential, as shown in the 
Research Pyramid illustration (Figure 0.1), with the pinnacle being that all colleagues actively support each other's research activities.

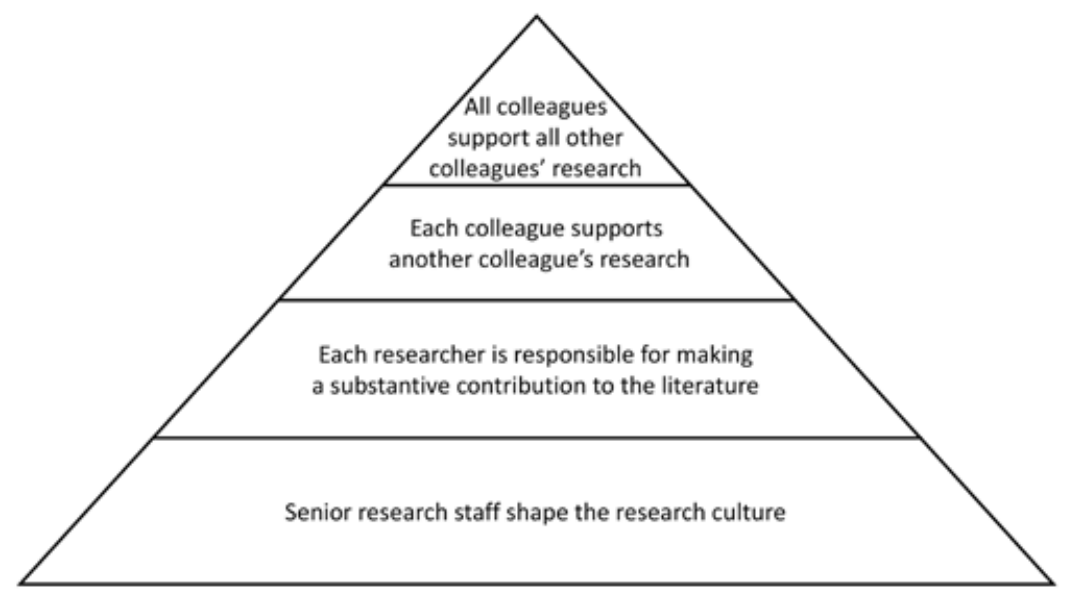

Figure $0.1 \quad$ The Research Pyramid

It is possible that the bottom two layers of the Pyramid are interchangeable, where researchers take responsibility for their own research and then collectively shape the research culture; this can work when the research leader and senior staff members do a poor job in creating a beneficial research atmosphere. It is also possible that the top two levels change order, and this is where everyone helps their colleagues, and this can change the behaviour of a colleague who is naturally selfish and self-absorbed so that they wake up and support their colleagues by following their example. The latter can also occur when a new member of staff joins a department. Part of this ordering is driven by the strength of social norms within the department.

A researcher should be promoted to a leadership role only if they have the skills and ability to construct an effective and supportive research culture. However, this key research leadership skill seldom seems to be the principal concern of those who decide who should lead a group of researchers. Instead, it is often the case that someone is promoted as a reward for their own research achievements rather than their ability to enable others to develop. ${ }^{43}$

It is possible that the achievements of the research leader are not of the type that others in the department value or respect (such as a trade-off between income generation and quality academic publications). A mismatch between types of achievement and research values will affect perceptions of the importance of particular types of research and can lead colleagues to perceive 
that their own research is no longer valued. Satisfaction levels of a leading researcher is important for the external recognition of the department, especially when they are attempting to recruit new high-flying staff, but the development and future achievements of a research group are ultimately influenced by the morale and job satisfaction of other researchers within the group. ${ }^{44}$

David Spencer's (2015) ${ }^{45}$ insightful investigations into the satisfaction of work emphasises that it is not just the work that is important for the individual but also the context and organisation of the work that makes it meaningful. Vice Chancellors, Faculty Deans and Associate Deans need to decide on and shape the type of research culture that they want within their faculties and departments, and then recruit appropriate research leaders to implement that culture, perhaps driven by their desire to make a change. ${ }^{46}$ For instance, do these senior persons want to create a community of practice ${ }^{47}$ or a set of competing individuals? A successful research-focused team needs to work together effectively with a united front for the greater good.

\section{NEWTONIAN VERSUS DARWINIAN DEVELOPMENT}

So how do researchers get better at what they do? How do they become great at research? There are two contrasting yet dominant perspectives in this literature. The pedagogical perspective states that someone purposefully learns something, applies those ideas, reapplies those ideas and becomes more efficient and more effective at doing so. Some lawyers, contract researchers, scientists, etc. do it this way: they learn the path and then apply those ideas. This Newtonian stance works for some, but it is not the guidance that I would give to post-doctoral social scientists who aspire to make a tangible contribution to society.

The alternative dominant perspective is that you do not simply learn and relearn something; instead, you need to draw on self-reflection in order to extricate yourself from your normal stance and disentangle yourself from your own biased assumptions. You need your colleagues to point out those gaps that you were not aware existed. You learn from others who think differently from yourself. You need to merge new information with what you already know, and then use this new knowledge to push forward your own social scientific investigations. In other words, researchers should remain free, responsible and self-critical in order to conceive and develop their own ideas. Similarly, they need to aid and supportively stimulate the rumination of their colleagues' ideas.

The former perspective pushes the research path forward, but not necessarily in the direction of interest to the researcher; it is useful for contract research, is functional and can be instrumental, but it does not necessarily make a substantive contribution to the development of knowledge. Instead, try to ensure that 
you make substantive contributions to the literature. Researchers need time for reflection as well as the presence of supportive and constructively critical feedback that pushes us in the direction that we are intrinsically motivated to investigate. We need to be reminded what is worth doing, what is important, what is interesting, what is useful for society and what is pedantic. There is a place in academia for purely academic research in the same way that there is space for purely practice-oriented research. We need people to observe our research, and to provide us with constructively critical feedback, to nudge us in the right direction even when that nudge can feel uncomfortable.

Start with what is right rather than what is acceptable. (Franz Kafka)

Seemingly randomly occurring nudges can be very uncomfortable experiences, sometimes embarrassingly so, and can make us not want to do something again. Subsequent reconsideration of those nudges with a reflective mind can help us move in the right direction and will make us stronger ... eventually. Some colleagues, even if they have their heart in the right place, will appear to be trying to gain brownie points by belittling us when we present an open talk, such as in a staff seminar or during a conference speech. Those belittling colleagues do this because they need to feel superior to you, and that is because they lack self-worth. Some academic conference circuits even have this type of behaviour engrained in their culture. ${ }^{48}$ People in the audience will know that an arrogant delegate in the audience is being a jerk when they ask and phrase a particular question in a derogatory way; those audience members will reticently take pity on the presenter but may not admit to it due to social pressures to conform to an academic culture. Nevertheless, the vast majority of people in the audience will be on your side and will want you to learn from the mistakes that we all make from time to time, because they have been in your position too, and because they will have learned from the experience irrespective of how small the experience made them feel.

What doesn't kill you makes you stronger. (Genghis Kahn) ${ }^{49}$

Irrespective of how good or bad the people are around you, try to find the power within yourself to recognise and embrace healthy criticism whenever it comes your way. When you have the trust of your research mentor who believes unreservedly in your capability and what you will achieve eventually, then you should have the belief that you can develop and progress. ${ }^{50}$ After all, 
some of the most powerful lessons to learn in life are only presented in the form of setbacks.

The greatest glory in living lies not in never falling, but in rising every time we fall. (Nelson Mandela)

\section{STRUCTURE OF THIS BOOK}

This book has ten sections with each section containing ten tips. The first section highlights indispensable points that are vital for a strong research career and for an active, supportive and constructively critical research culture. These ten tips may appear trivial and second nature to established researchers who are based in departments that already have these characteristics, but they are all too easy to lose sight of, trivialise, ignore and not value. These are things that the department should support, get right as a priority and install as habits in all of their colleagues.

The next three sections highlight practices that individual researchers should engage in, and which research leaders should encourage. It is paramount that the research leader consistently reflects on whether their colleagues are practising these good behaviours and appraise whether there is anything they can do to strengthen these activities.

The following three sections focus on the benefits of collaboration and the wide range of collaborative covert and overt behaviours that exist when giving and receiving support and advice. The last three sections focus on the leveraging of benefits for research from teaching, external grant capture and knowledge exchange. If these activities are carried out efficiently and effectively, there are enormous benefits for the researcher, for their research trajectory and for the benefit of society. However, if these interconnections are misunderstood, if external funders exploit their incentivising position or if the researcher gets distracted by other newly found initiatives, external grants and knowledge exchange activities can be at a cost to their own and their department's research trajectory. The lessons provided within those three sections could help drive forward even the best research-active departments. ${ }^{51}$ Each tip is discussed first by stating the idea and what is good practice. Each tip then proceeds by stating why this is good practice and when this practice should be implemented. Emphasis is placed on how a research leader can enable and encourage these practices within the department. Note that each of these three segments varies in importance depending on the topic, and this is reflected in the text.

A research leader can stimulate and motivate research-active colleagues, and they can construct soft supportive structures that integrate staff into a collaborative culture. However, they can also destroy soft, motivating and 
supportive structures, which can then extinguish a research culture and reduce researchers' confidence, and thereby depress research output and researcher flow. A positive research culture takes years to build and a short time to wipe out.

Real positive step change in research and in a research culture occurs when people interact and help each other. We need productive disagreement, as real progress and creativity depend on it. But disagreement does not mean that we should tolerate incivility; quite the opposite, as we are more likely to listen, acknowledge, recognise unintended consequences and even comprehend an awareness of contending perspectives when we are civil.

I hope you find this book useful, but if you do not find it useful, and that may be because you already run or work in a successful research-focused department or because you disagree with the importance of these tips, then please pass this book on to someone who could benefit from it. If you and/or your department are not achieving what you had hoped for, then perhaps the good practices that you thought were installed in the behaviour of yourself and of your colleagues are not being adopted effectively, or followed closely enough, or maybe that structure is the wrong one for your colleagues. Perhaps your department is too competitive and not collaborative enough.

Finally, to develop as a researcher and as a research-focused department you need to have the right balance between individual and collective attitudes. A first-class and high-achieving department will have a research culture based on a collection of attitudes that nurtures and reproduces a genuine drive for knowledge for the common good. That is why we should help each other to perform at and achieve our best, to rediscover our best when we lose it, and to reinforce each other's enjoyment and interests in a topic and in our journey together.

\section{Good luck!!}

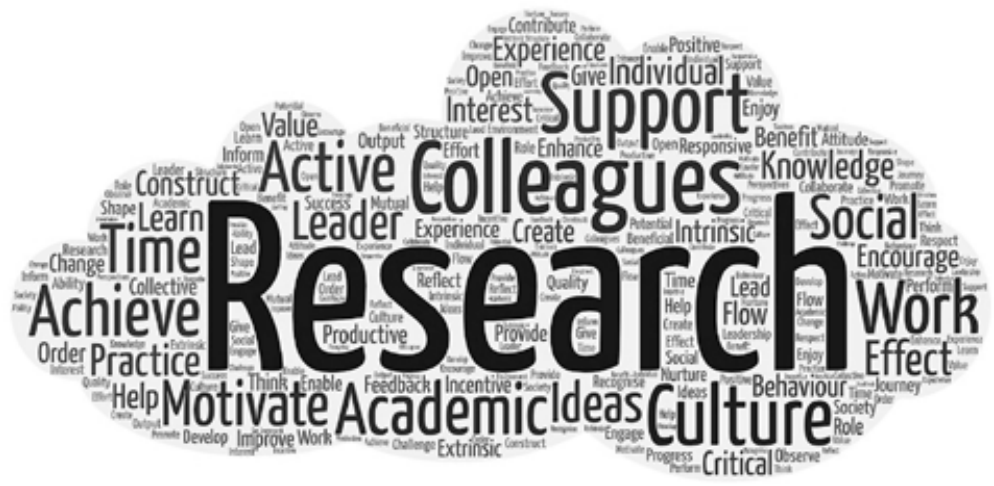

Figure 0.2 The Research Wordcloud 


\section{NOTES}

1. This book does not present the results of a research project that sought to identify the dynamic implications of particular policies to enhance research; given the enormity of such a project, it would inevitably have been case- or time-specific.

2. Lopes, H. (2011), 'Why do people work? Individual wants versus common goods', Journal of Economic Issues, 45(1), pp. 57-73.

3. Turban, D. B. and Yan, W. (2016), 'Relationship of eudaimonia and hedonia with work outcomes', Journal of Managerial Psychology, 31(6), pp. 1006-20.

4. Kahneman, D. (2012), Thinking, Fast and Slow, Penguin Books.

5. If you do not enjoy your research, then you will never reap the rewards of flow in your research. Flow will not come to you when you are discontented or demoralised; you will not achieve your research potential; you will not achieve that four-star publication that you yearn for; you may even stop yearning for improvement because you begin to believe that you will never achieve it. If your happiness is not present, then your flow will be lost. Do not be trapped in a job that you absolutely hate - it will drain you of all energy, enjoyment and fulfilment, and you will be letting yourself down, your favoured research career down, your department down, your discipline down, and society will not be able to benefit from your research. Know when it is time for a change. The difficulty, of course, is finding a better and convenient alternative. Ultimately, you only excel at what you enjoy.

6. Notice that when our motivation wanes, and motivation comes and goes, we end up only doing the easiest things that require the least amount of effort. See Carter, C. (2021), 'The 1-minute secret to forming a new habit', TED Talk, https://www.ted.com/talks/christine_carter_the_1_minute_secret_to_forming_a new_habit\#t-379977.

7. If line managers increase workloads or impose new things to do that are not consistent with a researcher's main interests or skill set, then the repercussion will be a lower quality or lower quantity of research. Differences in workloads may be an important reason for the gap in research quality and research output between research-intensive and teaching-intensive universities. After all, it is not where you trained for your doctorate that matters for your research output, but where you work. See Way, S. F., Morgan., A. C., Larremore, D. B. and Clauset, A. (2019), 'Productivity, prominence, and the effects of academic environment', Proceedings of the National Academy of Sciences of the United States of America, 116(22), pp. 10729-33. If teaching-intensive universities want to increase their research output, they must stop giving those researchers new or more duties.

8. Poggi (2010) argues that the personal gap between how we feel we are doing and what we aspire to do is what drives job satisfaction. See Poggi, A. (2010), 'Job satisfaction, working conditions, and aspirations', Journal of Economic Psychology, 31(6), pp. 936-49.

9. Maslow, A. H. (1943), 'A theory of human motivation', Psychological Review, 50(4), pp. 370-96.

10. Amy Milton is a behavioural neuroscientist and argues in her TED Talk that high levels of stress stop us storing details of events. See https://www.ted.com/talks/amy_milton_can_we_edit_memories?language=en. It is possible that researchers under high levels of stress may not focus on the what, 
where and when effectively enough. Ensuring that a researcher is under a low level of stress may enable them to achieve their potential faster.

11. Akinola, M. and Wilson, R. (2020), 'Train yourself to shine under stress', TED Talk, https://podcasts.apple.com/us/podcast/train-yourself-to-shine-under-stress -russell-wilson/id470622782? $\mathrm{i}=1000502290737$.

12. See BBC (2018), 'Is boasting good or bad for business?' www.bbc.co.uk.news/ business-43060675.

13. Of course, this is consistent with Maslow's (1943) idea that the social value of cooperation itself can fulfil human needs. See Maslow, A. H. (1943), 'A theory of human motivation', Psychological Review, 50, pp. 370-96.

14. For an excellent book on the connections between flow and happiness, see Csikszentmilalyi, M. (2002), Flow: The Psychology of Happiness, Rider Publishers.

15. Paine, T. (2009 [1794]), The Age of Reason: The Complete Edition, World Union of Deists.

16. See Freud, S. (2012 [1921]), Group Psychology and the Analysis of the Ego, Empire Books.

17. See Kahnweiler, J. (2018), Introverted Leader: Building on Your Quiet Strength, Berrett-Koehler Publishers.

18. Dolan, P. and Kudrna, L. (2016), 'Sentimental hedonism: pleasure, purpose and public policy', in Vittersø, J., Handbook of Eudaimonic Well-Being, Springer.

19. See, for instance, Kane, R. L., Johnson, P. E., Town, R. J. and Butler, M. (2004), 'A structured review of the effect of economic incentives on consumers' preventive behaviour', American Journal of Preventative Medicine, 24, pp. 327-52.

20. Frey, B. S. (1993), 'Shirking or work morale? The impact of regulating', European Economic Review, 37(8), pp. 1523-32.

21. Ariely, D., Gneezy, I., Loewenstein, G. and Mazar, N. (2009), 'Large stakes and big mistakes', Review of Economic Studies, 76, pp. 451-69. Ariely is an example of a person deeply intrinsically engaged with his topic for personal reasons and at the highest professional standard. This is the best mix of engagement where heart and mind are together.

22. Bowles, S. (2008), 'Policies designed for self-interested citizens may undermine "The Moral Sentiments": evidence from economic experiments', Science, 320(5883), pp. 1605-9.

23. Nosek, B. A., Spies, J. R. and Motyl, M. (2012), 'Scientific utopia', Perspectives on Psychological Science, 7(6), pp. 615-31.

24. Smaldino, P. E. and McElreath, R. (2012), 'The natural selection of bad science', Royal Society Open Science, 3, 160384. This can be accessed at https://ro yalsocietypublishing.org/doi/pdf/10.1098/rsos.160384

25. Ariely, D., Meier, S. and Rey-Biel, P. (2011), 'When and why incentives (don't) work to modify behavior', Journal of Economic Perspectives, 25(4), pp. 191-210.

26. Titmuss, R. M. (1970), The Gift Relationship, Allen and Unwin.

27. Böckerman, P., Bryson, A., Kauhanen, A. and Kangasniemi, M. (2020), 'Does job design make workers happy?' Scottish Journal of Political Economy, 67(1), pp. 31-52.

28. There is no point in being a rotten kid; see Becker, G. S. (1981), A Treatise of the Family, Harvard University Press.

29. Deci, E. L. and Ryan, R. M. (2000), "The "what" and "why" of goal pursuits: human needs and the self-determination of behaviour', Psychological Inquiry, 11(4), pp. 227-68. 
30. These issues are in addition to the Peter and Paula Principles. See Schuller, T. (2017), The Paula Principle: How and Why Women Work Below Their Level of Competence, Scribe; Peter, L. J. and Hull, R. (1969), The Peter Principle: Why Things Always Go Wrong, William Morrow and Co.

31. See Burns, J. M. (2004), Transformational Leadership: A New Pursuit of Happiness, Grove Press.

32. See Robert Reffkin's TED video for an upbeat and short summary. This can be accessed at https://www.ted.com/talks/robert_reffkin_5_ways_to_create_stronger connections\#t-157396.

33. For instance, on 9 February 2020, the American Economic Association sent an email to its members to state that it had "taken several important steps to improve the professional climate in economics. As part of this continuing effort, today I am pleased to report on establishing a set of guidelines for investigating complaints that officers and/or members of the Association have violated the Association's Code of Conduct and Policy on Harassment and Discrimination. The AEA Code of Professional Conduct, adopted by the Executive Committee in April 2018 after consultation with the membership, was supplemented by a more detailed Policy on Harassment and Discrimination, also ratified by the Executive Committee. Acknowledgment and acceptance of both the Code and the harassment and discrimination policy is now required for participation in any AEA-sponsored activity or committee. During 2019, AEA members voted to amend the AEA bylaws to add a provision so that a member and/or officer who violates the Code or the Policy may be sanctioned or membership may be terminated as voted by a two-thirds majority vote of the Board of Trustees. The amended bylaws can be read in their entirety at https://www.aeaweb.org/resources/member -docs/certificate-of-incorporation-bylaws. The new guidelines for investigating complaints, and, if necessary, imposing sanctions, have been approved by the Executive Committee and are effective immediately. They are posted on the AEA website at https://www.aeaweb.org/go/policy-hd/procedures. Instructions for filing formal complaints with the Association's Ethics Committee, and for consulting with the AEA Ombudsperson about potential complaints, are also available at https://www.aeaweb.org/go/policy-hd/formal-complaint and https://www.aeaweb .org/about-aea/aea-ombudsperson/faq. The Association remains committed to improving the professional climate in economics and considers the adoption of these guidelines another important step in helping make my field accessible and welcoming to anyone with the interest and ability to make a career in it. I ask for the support of all members in these efforts."

34. Bland, C. J., Center, B. A., Finstad, D. and Staples, J. G. (2005), 'A theoretical, practical, predictive model of faculty and department research productivity', Academic Medicine, 80(3), pp. 225-37.

35. Ryan, J. and Hurley, J. (2007), 'An empirical examination of the relationship between scientists' work environment and research performance', $R \& D$ Management, 37(4), pp. 345-54.

36. Clarke, M., Kenny, A. and Loxley, A. (2015), 'Creating a supportive working environment for academics in higher education', Country Report Ireland, The Teachers' Union of Ireland and Irish Federation of University Teachers, Dublin.

37. Lohela-Karlsson, M., Hagberg, J. and Bergström, G. (2014), 'Production loss among employees perceiving work environment problems', International Archives of Occupational and Environmental Health, 88(6), pp. 769-77.

38. Jacoby, S. (2009), The Age of American Unreason, Vintage Books. 
39. Thaler, R. and Sunstein, C. (2008), Nudge, Penguin Books.

40. Benson, A., Li, D. and Shue, K. (2019), 'Promotions and the Peter principle', Quarterly Journal of Economics, 134(4), pp. 2085-134.

41. A very interesting result is reported by Way et al. (2019) who show that the scientific productivity of academics depends not on where they trained for their doctorate but instead on where they work; it is therefore the workplace that shapes and nurtures talent and enables colleagues to achieve, and not where they studied their degrees. See Way, S. F., Morgan, A. C., Larremore, D. B. and Clauset, A. (2019), 'Productivity, prominence, and the effects of academic environment', Proceedings of the National Academy of Sciences of the United States of America, 116(22), pp. 10729-33.

42. The moral valence of cooperative behaviour is uniformly positive; see Curry, O. S., Mullins, D. A. and Whitehouse, H. (2019), 'Is it good to cooperate? Testing the theory of morality-as-cooperation in 60 societies', Current Anthropology, 60(1), pp. 47-69.

43. These issues are in addition to the Peter and Paula Principles. See Schuller (2017), The Paula Principle; Peter and Hull (1969), The Peter Principle.

44. The BBC writes (https://www.bbc.co.uk/sport/football/51962924) that the reason Wolverhampton Wanderers Football Club are competing to be sixth in the English Premier League is because its manager, Nuno Espírito Santo, has a focus on team morale and team bonding. Since the start of his coaching career, the Portuguese manager has placed great emphasis on tight-knit squads. There has been an emphasis on creating a small, unified group of players to make up the first team and his awareness of the importance of keeping everyone involved is likely to be a consequence of his own playing experience. Keeping all of the squad onside is an important part of Nuno's philosophy and his office is always open to those seeking advice or to discuss any part of football or life. (22 March 2020).

45. Spencer, D. A. (2015), 'Developing an understanding of meaningful work in economics: the case for a heterodox economics of work', Cambridge Journal of Economics, 39, pp. 675-88.

46. Teaching-focused institutions will prioritise enhancing their teaching provision using structures designed to ensure high-quality teaching. Research-focused institutions will prioritise academic research and compete for prestigious research funds to compete in the international rankings of research-intensive universities. Other institutions will prioritise income generation, especially when they do not have a particular strength in either teaching or academic research. Increasingly, academic institutions are trying to compete in two or all three of these areas, thereby putting additional pressure on staff.

47. See https://www.advance-he.ac.uk/knowledge-hub/communities-practice. See also Lave, J. and Wenger, E. (1991), Situated Learning: Legitimate Peripheral Participation, Cambridge University Press; Kimble, C., Hildreth, P. and Bourdon, I. (2008), Communities of Practice: Creating Learning Environments for Educators, Information Age Publishing.

48. For one potential example of many, see note 33.

49. Alternatively, Friedrich Nietzsche famously said, "That which does not kill you, makes you stronger."

50. When Adrián San Miguel del Castillo (known as Adrián) moved to Liverpool Football Club on a free transfer on 5 August 2019, it was a surprise to many that he made his debut after being at the club for only four days when he replaced Allison (the club's first-choice goalkeeper) after 39 minutes due to an injury to 
Allison. Writing on the BBC website and responding to the interviewer's question of "did Klopp have anything else to add [when he was about to make his debut]?", Adrián states that "He hugged me. He showed me I had his trust ... the way the fans embraced me in such a critical moment ... They gave me total confidence." Commenting further about Jürgen Klopp, Adrián continues by saying, "It is so easy working with him. So easy. He's always smiling, cheerful, optimistic. ... He's there to guide us. He visualises football very well from the sidelines and transmits this knowledge to the players in a masterful way." Clearly this approach can work in a variety of settings. This is consistent with empirical findings that optimism fuels social cooperation (Oyediran et al., 2018) and that cooperation can enhance productivity. See Oyediran, O. A., Rivas, M. F., Coulson, M. and Kernohan, D. (2018), 'Cooperation and optimism in social dilemma', Bulletin of Economic Research, 70(4), 335-40.

51. This is the case in the UK where we will soon have a Knowledge Exchange Framework (KEF) in addition to the Teaching Excellence and Student Outcomes Framework (TEF) and the Research Excellence Framework (REF). 